\title{
Comunicação
}

[Communication]

\section{Conidiobolomicose em ovinos: reavaliação de três casos previamente diagnosticados como tumor etimoidal enzoótico}

[Conidiobolomycosis in sheep: reevaluation of three cases previously diagnosed as enzootic ethmoid tumor]

\author{
S.M.M.S. Silva ${ }^{1,2}$, L.H. Ferreira ${ }^{1}$, F.A.L. Souza ${ }^{2}$, E.F. Nascimento $^{1}$, E.A. Costa $^{1}$, \\ T.A. Paixão ${ }^{3}$, R.L. Santos ${ }^{1 *}$ \\ ${ }^{1}$ Escola de Veterinária - UFMG \\ Av. Antônio Carlos, 6627 \\ 31270-901 - Belo Horizonte, MG \\ ${ }^{2}$ Centro de Ciências Agrárias - UFPI - Teresina, PI \\ ${ }^{3}$ Instituto de Ciências Biológicas - UFMG - Belo Horizonte, MG
}

A conidiobolomicose é uma zigomicose causada por fungos do gênero Conidiobulus spp., que estão frequentemente associados à rinite granulomatosa em humanos e animais. Estes fungos saprófitas, pertencentes à ordem Entomopthorales e classe Zigomycetes, são encontrados no solo e na vegetação decomposta e com parasitas de insetos em regiões tropicais e subtropicais (Carrigan et al., 1992). Em animais, a enfermidade pode ser causada por Conidiobolus coronatus, C. lamprageus ou C. incongruus (Carrigan et al., 1992; Morris et al., 2001; Silva et al., 2007a).

Nos ovinos, a enfermidade caracteriza-se clinicamente por apatia, anorexia, dificuldade respiratória, descarga nasal, exoftalmia, assimetria craniofacial, febre e respiração ruidosa (Silva et al., 2007b), e os animais apresentam aumento da frequência respiratória e cardíaca. As alterações comumente observadas no hemograma e na bioquímica sérica são anemia, leucocitose com neutrofilia, hipoproteinemia, hipomagnesemia, hipocalcemia, hiperfosfatemia, hipoglicemia, hiperbilirrubinemia, aumento da atividade sérica de aminotransferase e glutamiltransferase e diminuição da ação da fosfatase alcalina (Batista et al., 2009). Macroscopicamente, observa-se na região etmoidal material irregular, granular, friável e amarelado, que pode estender-se até a órbita, placa cribiforme e seio frontal, causando exoftalmia e assimetria craniofacial. A lesão pode invadir a região frontal, do cérebro e/ou afetar pulmões, linfonodos regionais, rins, coração e vesícula biliar (Silva et al., 2007a). Microscopicamente, as lesões consistem em granulomas multifocais, com área central necrótica, contendo hifas de paredes finas, raramente septadas e com ramificações laterais, rodeadas por material de Splendore-Hoeppli (Carrigan et al., 1992).

Vale salientar que, durante muito tempo, a doença foi diagnosticada como tumor etmoidal enzoótico (Nascimento et al., 1979), mas recentemente foi comprovado, por estudos histopatológicos, histoquímicos, imunoistoquímicos e microbiológicos, que se trata de uma infecção por Conidiobolus coronatus denominada conidiobolomicose (Silva et al., 2007a). Em pesquisa recente, Vilela et al. (2010) sequenciaram algumas amostras oriundas do estado do Piauí, onde as caracterizaram como Conidiobolus lamprageus. $\mathrm{O}$ objetivo deste trabalho foi descrever três casos de conidiobolomicose previamente diagnosticados como tumor etimoidal enzoótico.

Em maio de 1979, foram encaminhadas para a Escola de Veterinária da Universidade Federal de Minas Gerais amostras da cavidade nasal,

Recebido em 6 de junho de 2010

Aceito em 6 de dezembro de 2010

*Autor para correspondência (corresponding author)

E mail: rsantos@vet.ufmg.br 
pulmões, glândula parótida e linfonodos para diagnóstico histopatológico. As amostras eram provenientes de três ovinos: um macho de 18 meses da raça Santa Inês, um macho de 12 meses da raça Morada Nova, ambos procedentes do município de Campo Maior, Piauí, e uma fêmea adulta da raça Santa Inês, de Sobral, Ceará. O diagnóstico, na época para os três casos, foi de tumor etmoidal enzoótico. Em 2010, esse material foi resgatado para uma nova análise histológica e realização de histoquímica e imunoistoquímica. Cortes de $5 \mu \mathrm{m}$ de espessura foram corados com hematoxilina e eosina (HE), prata metanamina de Grocott (GMS) e ácido periódico de Schiff (PAS). A imunoistoquímica foi realizada em tecido parafinizado utilizando-se anticorpo anticitoqueratina humana (clone AE1/AE3 diluição 1:100 - Dako, EUA).

As lesões macroscópicas descritas eram cavidades nasais contendo massa de aspecto tumoral amarelo-brancacenta, friável, de aspecto nodular e superfície irregular, a qual invadia os cornetos e septos nasais, os seios paranasais e o osso frontal. Estes achados macroscópicos são compatíveis com os casos de conidiobolomicose descritos nos estados do Piauí (Silva et al., 2007a), Paraíba (Riet-Correa et al., 2008), Mato Grosso (Boabaid et al., 2008) e Rio Grande do Sul (Pedroso et al., 2009). Na microscopia, abaixo do epitélio dos cornetos nasais, observouse uma reação inflamatória caracterizada por granulomas multifocais a coalescentes. Os granulomas eram constituídos por uma área central de necrose circundada por infiltrado linfoistiocitário e eosinofílico, macrófagos epitelioides, células gigantes multinucleadas e hifas com citoplasma eosinofílico (Fig. 1). Havia, ainda, algumas áreas de necrose multifocal. Observaram-se imagens negativas de hifas circundadas por material eosinofílico radiado, caracterizando o fenômeno de Splendore-Hoeppli (Fig. 2). As trabéculas ósseas foram absorvidas e substituídas por grande quantidade de tecido fibroso. Essas lesões foram observadas nos três ovinos e são semelhantes às descritas em ovinos infectados com $C$. incongruus (Carrigan et al., 1992) e C. coronatus (Silva et al., 2007a). Um dos ovinos apresentou nodulações pulmonares - microscopicamente semelhantes às lesões da cavidade nasal, embora com menor quantidade de hifas e células gigantes -, rara infiltração eosinofílica e mineralização multifocal próxima às áreas de necrose. As lesões histopatológicas da glândula parótida e linfonodo observadas em um dos ovinos também foram semelhantes às encontradas na cavidade nasal. A coloração de GMS realizada nos cortes de cavidade nasal, pulmões e parótida revelou a presença de hifas largas com afinidade pela prata de parede fina, com septos escassos e dilatação balonosa na extremidade em todos os três ovinos (Fig. 3). Na coloração por PAS, as hifas apresentavam-se róseas, PAS positivas (Fig. 4), compatíveis com o gênero Conidiobolus (Silva et al., 2007a; Boabaid et al., 2008).

Na imunoistoquímica, não foi observada imunomarcação citoplasmática para citoqueratina nas áreas das lesões em nenhum dos três ovinos, sendo observada marcação citoplasmática intensa e difusa somente no epitélio, o qual se encontrava íntegro. Estes achados comprovam que a lesão não tem característica proliferativa epitelial, e sim inflamatória granulomatosa (Fig. 5 e 6) (Geninet et al., 2003). É importante realizar o diagnóstico diferencial de tumor etmoidal enzoótico, que, embora tenha localização anatômica e aspecto macroscópico semelhantes à conidiobolomicose em ovinos, apresenta curso clínico mais prolongado e diferentes lesões microscópicas (McKinnon et al., 1982). Dessa forma, a reação de imunoistoquímica foi realizada para confirmar o fato de essas lesões não serem neoplásicas, mas sim inflamatórias. Com base nos achados histopatológicos, histoquímicos e imunoistoquímicos, confirma-se o diagnóstico de conidiobolomicose em ovinos, o qual havia sido previamente diagnosticado como tumor etmoidal enzoótico no ano de 1979 (Nascimento et al., 1979).

Palavras-chave: ovino, conidiobolomicose, tumor etmoidal enzoótico 


\section{Conidiobolomicose em ovinos...}

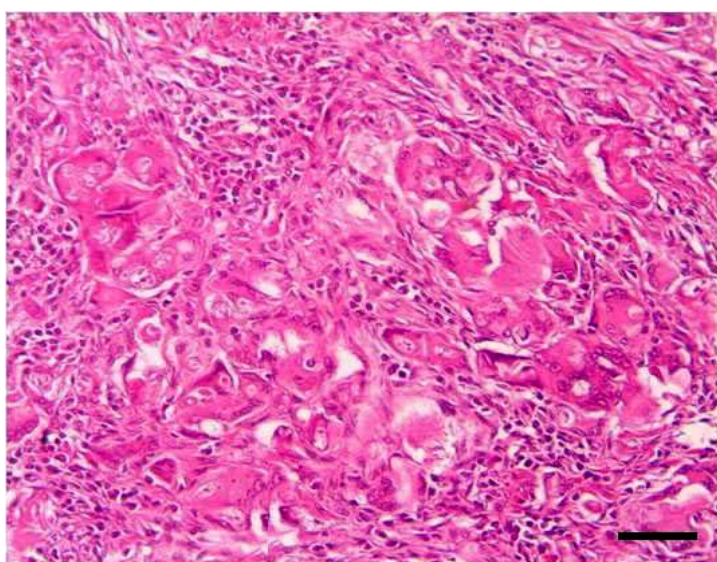

Figura 1. Ovino. Cavidade nasal com reação inflamatória granulomatosa caracterizada por infiltração de macrófagos, linfócitos e células gigantes, com fagocitose de hifas em imagem negativa. H.E. Barra $=75 \mu \mathrm{m}$.

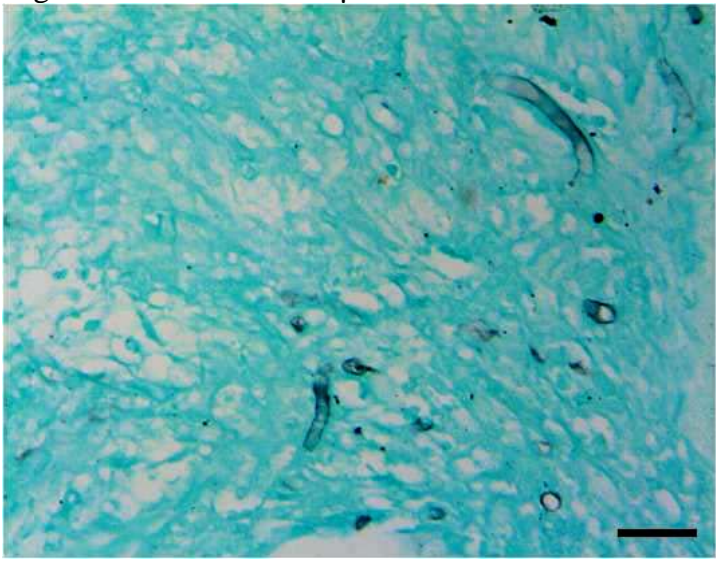

Figura 3. Ovino. Cavidade nasal com hifas de contornos enegrecidos cortadas longitudinal e transversalmente. GMS. Barra $=75 \mu \mathrm{m}$.

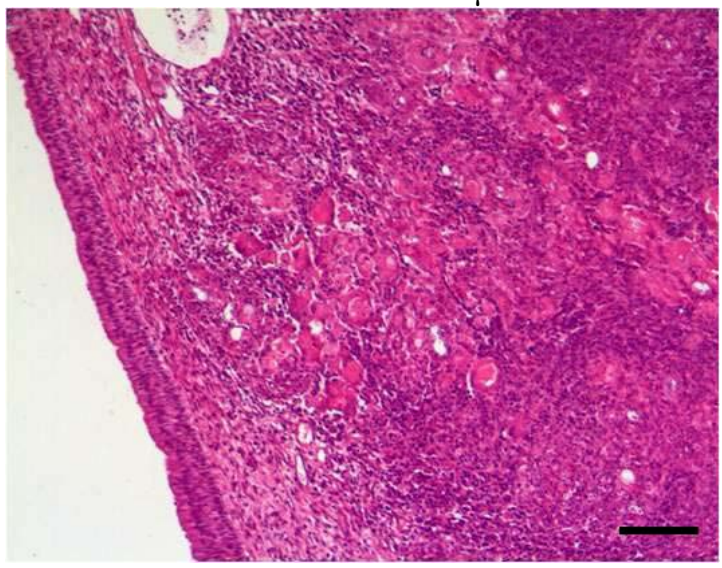

Figura 5. Ovino. Cavidade nasal com reação inflamatória granulomatosa abaixo de epitélio íntegro. H.E. Barra $=75 \mu \mathrm{m}$.

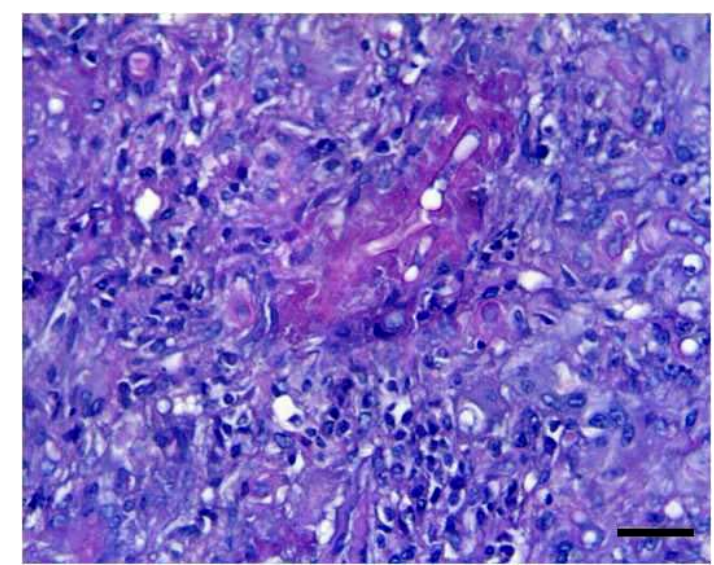

Figura 2. Ovino. Pulmões com reação inflamatória granulomatosa e hifas circundadas por material eosinofílico PAS positivo caracterizando fenômeno de Splendore-Hoeppli. PAS. Barra $=150 \mu \mathrm{m}$.

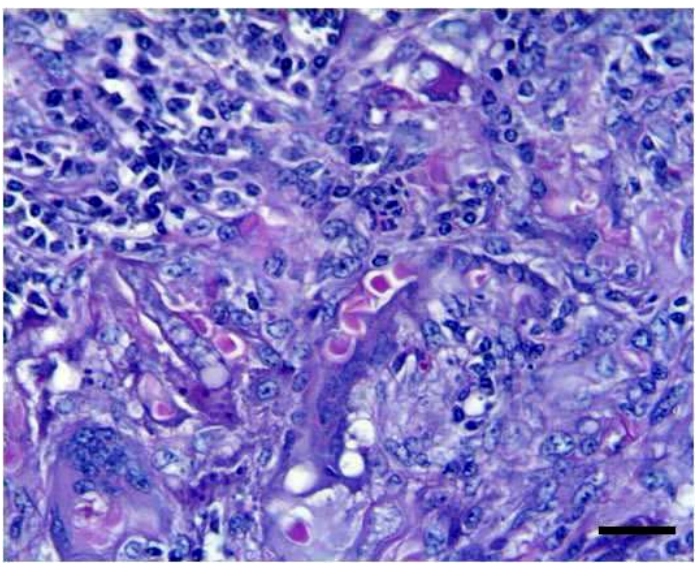

Figura 4. Ovino. Cavidade nasal com hifas de coloração rósea PAS positiva. PAS. Barra $=150 \mu \mathrm{m}$.

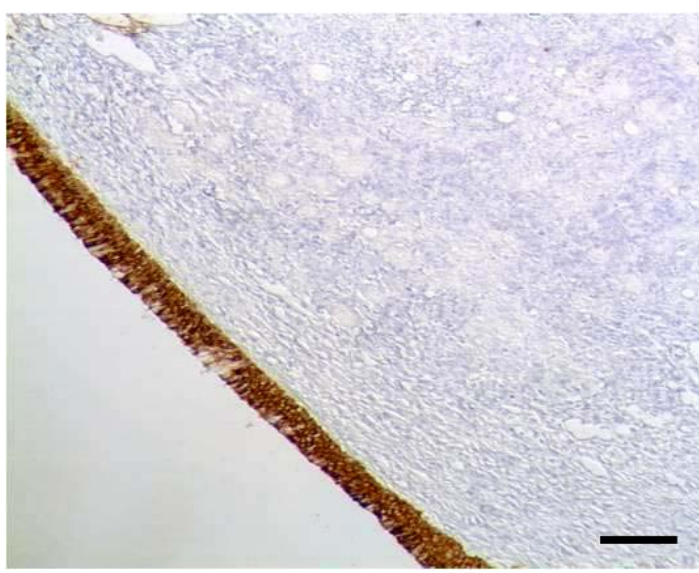

Figura 6. Ovino. Imunomarcação positiva para citoqueratina do epitélio de revestimento e negativa da lesão granulomatosa localizada abaixo do epitélio. Imunoperoxidase. Barra $=75 \mu \mathrm{m}$. 


\begin{abstract}
Conidiobolomycosis is an infection caused by fungi of the genus Conidiobolus spp. that is associated with a granulomatous rhinitis in humans and animals. In sheep, the disease is clinically characterized by respiratory changes, exophthalmia, craniofacial asymmetry, and fever. Microscopically, there are multifocal granulomas containing intralesional hyphae. For a long time, this disease was diagnosed as Enzootic Ethmoid Tumor. This report described three cases of conidiobolomycosis that had been previously diagnosed as Enzootic Ethmoid Tumor. Samples of nasal cavity, lung, parotid gland, and lymph node from three sheep submitted to histopathological examination in 1979 were retrieved in 2010 for a new histological, histochemical, and immunohistochemical evaluations. Paraffin-embedded tissue sections were stained with Hematoxylin-Eosin, Grocott's Metanamine Silver, and Periodic Acid Schiff. Immunohistochemistry was performed on paraffin embedded tissues using anti-cytokeratin primary antibody. Based on histopathology, histochemistry, and immunohistochemistry, the diagnosis of conidiobolomycosis was confirmed in three sheep, which had been previously diagnosed as Enzootic Ethmoid Tumor in 1979.
\end{abstract}

Keywords: sheep, conidiobolomycosis, enzootic ethmoid tumor

\section{AGRADECIMENTOS}

À Adriana Amantino M. Martins, pelo apoio técnico. EACe RLS são bolsistas do CNPq. RLS é atualmente fellow da John Simon Guggenheim Memorial Foundation. Este trabalho teve suporte do CNPq, da FAPEMIG e da CAPES (Programa PROCAD).

\section{REFERÊNCIAS BIBLIOGRÁFICAS}

BATISTA, M.C.S.; CASTRO, R.S.; REGO, E.W. et al. Hemograma, proteinograma, ionograma e dosagens bioquímicas e enzimáticas de ovinos acometidos por conidiobolomicose no Nordeste do Brasil. Pesq. Vet. Bras., v.29, p.1724, 2009.

BOABAID, F.M.; FERREIRA, E.V.; ARRUDA, L.P. et al. Conidiobolomicose em ovinos no estado de Mato Grosso. Pesq. Vet. Bras., v.28, p.77-81, 2008.

CARRIGAN, M.J.; SMALL, A.C.; PERRY, G.H. Ovine nasal zygomycosis caused by Conidiobolus incongruus. Aust. Vet. J., v.69, p.237-240, 1992.

GENINET, C.; BERNEX, F.; RAKOTOVAO, F. et al. Sclerosin peritoneal mesothelioma in a dog - a case report. J. Vet. Med. A, v.50, p.402-405, 2003.

McKINNON, A.O.; THORSEN, M.A.; HAYES M.A. et al. Enzootic nasal adenocarcinoma of sheep in Canadá. Can. Vet. J., v.23, p.88-94, 1982.
MORRIS, M.; NGELEKA, M.; ADOGWA, A. O. et al. Rhinocerebral zygomycosis in a sheep. Can. Vet. J., v.42, p.227-228, 2001.

NASCIMENTO, E.F.; REIS, R.; CARVALHO, A.U. et al. Tumor etmoidal enzoótico em ovinos. Arq. Esc. Vet. UFMG, v.32, p.337-342, 1979.

PEDROSO, P.M.O.; RAYMUNDO, D.L.; BEZERRA JÚNIOR, P.S. et al. Rinite micótica rinofaríngea em um ovino Texel no Rio Grande do Sul. Acta Sci. Vet., v.32, p.181-185, 2009.

RIET-CORREA, F.; DANTAS, A.F.M.; AZEVEDO, E.O. et al. Outbreaks of rhinofacial and rhinopharyngeal zygomicosis in sheep in Paraíba, northeastern Brazil. Pesq. Vet. Bras., v.28, p.29-35, 2008.

SILVA, S.M.M.S.; CASTRO, R. S.; COSTA, F.A.L. et al. Conidiobolomycosis in sheep in Brazil. Vet. Pathol., v.44, p.314-319, 2007a.

SILVA, S.M.M.S.; CASTRO S.C.; COSTA, F.A.L. et al. Epidemiologia e sinais clínicos da conidiobolomicose em ovinos no estado do Piauí. Pesq. Vet. Bras., v.27, p.184-190, 2007b.

VILELA, R.; SILVA, S.M.; RIET-CORREA, F. et al. Morphologic and phylogenetic characterization of Conidiobolus lamprauges recovered from infected sheep. J. Clin. Microbiol., v.48, p.427-432, 2010. 